\title{
Annexin A2 is an independent prognostic biomarker for evaluating the malignant progression of laryngeal cancer
}

\author{
SHI LUO, CHUBO XIE, PING WU, JIAN HE, YAOYUN TANG, JING XU and SUPING ZHAO \\ Department of Otorhinolaryngology Head and Neck Surgery, Key Laboratory of Otolaryngology Critical Diseases, \\ Xiangya Hospital of Central South University, Changsha, Hunan 410008, P.R. China
}

Received December 16, 2016; Accepted July 7, 2017

DOI: $10.3892 /$ etm.2017.5298

\begin{abstract}
Due to the lack of a definite diagnosis, a frequent recurrence rate and resistance to chemotherapy or radiotherapy, the clinical outcome for patients with advanced laryngeal cancer has not improved over the last decade. Annexin A2 is associated with the invasion and metastasis of cancer cells. In the present study, it was demonstrated using differential proteomics analysis that Annexin A2 is highly expressed in laryngeal carcinoma tissues and this was confirmed using immunohistochemistry, which demonstrated that the expression of Annexin A2 in laryngeal carcinoma tissues was significantly higher than in healthy adjacent tissue. In addition, its potential predictive value in the prognosis of patients with laryngeal carcinoma was evaluated. The results demonstrated that Annexin A2 expression was significantly associated with tumor size, lymph node metastasis, distant metastasis and clinical stage. In addition, higher Annexin A2 expression was associated with a poor prognosis of patients with laryngeal cancer. Thus, the results of the present study indicate that Annexin A2 expression is an independent prognostic biomarker for evaluating the malignant progression of laryngeal cancer.
\end{abstract}

\section{Introduction}

Laryngeal cancer is the most common type of head and neck cancer and the morbidity and mortality rates from laryngeal cancer are increasing worldwide (1). There is currently no established method of diagnosing laryngeal cancer. Furthermore, patients with laryngeal cancer have a high rate of recurrence and often develop resistance to chemotherapy or

Correspondence to: Professor Ping Wu, Department of Otorhinolaryngology Head and Neck Surgery, Key Laboratory of Otolaryngology Critical Diseases, Xiangya Hospital of Central South University, 87 Xiangya Road, Changsha, Hunan 410008, P.R. China E-mail: csuwoodpink@126.com

Key words: laryngeal cancer, Annexin A2, biomarker, proteomic, prognosis radiotherapy; therefore, the clinical outcome for patients with advanced laryngeal cancer remains poor $(2,3)$. Thus, more effective diagnostic and therapeutic targets are required.

Annexin family proteins promote invasion and metastasis in several types of cancer, including breast cancer, esophageal carcinoma, liver cancer and nasopharyngeal carcinoma (4). However, different members of the Annexin family proteins are either up- or downregulated in cancer tissue, so different Annexins may perform different roles in specific types of cancer $(5,6)$. It has been demonstrated that Annexin A1 is associated with esophageal cancer and is overexpressed in laryngeal carcinoma cells; it may therefore progressively migrate from the nucleus towards the membrane during laryngeal tumorigenesis (7). By contrast, Annexin A2 is associated with breast cancer (8) and knockdown of Annexin A2 by RNA interference decreases the proliferation and invasion of breast cancer cells (9). Additionally, Annexin A2 is associated with prostate cancer, invasive cervical carcinoma and lung cancer (10). Similarly, Annexins A4 and A5 are highly expressed in laryngeal carcinoma, indicating that they may contribute to its onset and development (11). The aforementioned results indicate that Annexin A2 expression may be important in determining the invasion and metastasis of various types of cancer. However, it remains unknown whether Annexin A2 is associated with the development of laryngeal carcinoma and whether it may act as a prognostic biomarker.

In the present study, differential proteomics analysis indicated that Annexin A2 was highly expressed in laryngeal carcinoma and its increased expression was confirmed using immunohistochemistry in tissues taken from patients with laryngeal carcinoma. The predictive value of Annexin A2 in the prognosis of patients with laryngeal carcinoma was subsequently evaluated.

\section{Materials and methods}

Study population. A total of 209 laryngeal cancer tissue samples and 88 adjacent tissues were collected from patients undergoing surgery at the Department of Otorhinolaryngology Head and Neck Surgery, Xiangya Hospital of Central South University (Changsha, China) between February 2010 and December 2011. The patients included 120 males and 89 females, aged 38-88 years old. The clinical characteristics of the patients with laryngeal cancer are summarized 
in Table I. All the tissues were fixed with formalin for $4 \mathrm{~h}$ at $4^{\circ} \mathrm{C}$, embedded in paraffin and stored at $4^{\circ} \mathrm{C}$ prior to usage. An additional 5 laryngeal cancer tissue samples and 5 matched adjacent tissue samples were immediately frozen at $-150^{\circ} \mathrm{C}$ and used for proteomics analysis. Prior to sample collection, no participants received any therapy. The present study was approved by the Ethics Committee of Xiangya Hospital of Central South University and all the participants provided written informed consent for inclusion in the current study.

Proteomics analysis. Total proteins were extracted and purified from fresh tissues using a ReadyPrep ${ }^{\mathrm{TM}}$ Protein Extraction kit (GE Healthcare Bio-Sciences, Pittsburgh, PA, USA) following the manufacturer's instructions. A 2-D Quant kit (GE Healthcare Bio-Sciences) was used to determine the concentration of the total protein. Proteomics analysis was performed as previously described (12). Proteins (300 $\mu \mathrm{g})$ were separated using $12.5 \%$ two-dimensional polyacrylamide gel electrophoresis (2-DE). The $20-\mathrm{cm}$ immobilized $\mathrm{pH}$ gradient strips (pH 3-10) were loaded with samples and subjected to rehydration overnight. Samples containing $150 \mu \mathrm{g}$ protein for analytical gels and unlabeled samples containing $1 \mathrm{mg}$ protein were diluted to $450 \mu 1$ with rehydration solution (Promega Corp., Madison, WI, USA) and used for isoelectric focusing (IEF). Proteins $(60 \mu \mathrm{g})$ were separated by $12 \%$ SDS-PAGE, and then each gel was stained with Coomassie Brilliant Blue dye and scanned with UMAXpowerlook 1120 (Umax Data Systems, Inc., Taipei, Taiwan). The DeCyder software version 6.5 (GE Healthcare, Chicago, IL, USA) was used to spot-detect and determine the quantity, intergel matching and statistics. The statistical significance was assessed for each change in abundance using a one-way analysis of variance with a post hoc Tukey's test. Protein spots for which the mean ratio was $>1.5$-fold or $<-1.5$-fold were selected.

Immunohistochemical (IHC) staining assay. The expression of Annexin A2 was evaluated using IHC staining. IHC staining was performed as previously described (13). Briefly, the tissue sections ( $4 \mu \mathrm{m}$ thick) were deparaffinized and hydrated and then retrieved using citrate buffer in boiling water for $15 \mathrm{~min}$. Subsequently, sections were incubated with primary antibodies (mouse monoclonal anti-Annexin A2; cat. no. WH0000302M1; 1:200; Sigma-Aldrich; Merck KGaA, Darmstadt, Germany) overnight at $4^{\circ} \mathrm{C}$. Sections were then incubated with horseradish peroxidase conjugated-polymer anti-mouse secondary antibody (cat. no. KIT-5902; 1:200; Maxim Biotech, Inc., Rockville, MD, USA) for $60 \mathrm{~min}$ at $37^{\circ} \mathrm{C}$. Sections were then visualized using diaminobenzidine, counterstained with hematoxylin for $5 \mathrm{~min}$ at room temperature and observed under a light microscope (magnification, x100).

To measure the expression of Annexin A2 in tissues, the extent and intensity of staining were assessed in each section. All tissue sections were analyzed and scored independently by three experienced pathologists who were blinded to the experiments designed. Annexin A2 staining intensity was scored as 0 (negative, -), 1 (positive, weak, + ), 2 (positive, moderate, ++ ) and 3 (positive, strong, +++ ). The extent of staining was scored as $0-1.0(0-100 \%)$. The final staining score $(0-3)$ was calculated as the multiplication of the intensity score and extent score. The expression of Annexin A2 was determined to be high
Table I. Association between annexin A2 expression and clinicopathological variables in patients with laryngeal cancer.

\begin{tabular}{|c|c|c|c|}
\hline \multirow[b]{2}{*}{ Variables } & \multicolumn{2}{|c|}{ Annexin A2 } & \multirow[b]{2}{*}{ P-values } \\
\hline & $\begin{array}{c}\text { Low } \\
\text { expression } \\
(\mathrm{n}=89)\end{array}$ & $\begin{array}{c}\text { High } \\
\text { expression } \\
(\mathrm{n}=120)\end{array}$ & \\
\hline \multicolumn{4}{|l|}{ Age (years) } \\
\hline$<60$ & 45 & 65 & \multirow[t]{2}{*}{0.674} \\
\hline$\geq 60$ & 44 & 55 & \\
\hline \multicolumn{4}{|l|}{ Sex } \\
\hline Male & 50 & 70 & \multirow[t]{2}{*}{0.779} \\
\hline Female & 39 & 50 & \\
\hline \multicolumn{4}{|l|}{ Tumor size (cm) } \\
\hline$<5$ & 60 & 47 & \multirow[t]{2}{*}{$<0.001^{\mathrm{a}}$} \\
\hline$\geq 5$ & 29 & 73 & \\
\hline \multicolumn{4}{|l|}{ Histological grade } \\
\hline I & 57 & 83 & \multirow[t]{2}{*}{0.460} \\
\hline II-III & 32 & 37 & \\
\hline \multicolumn{4}{|l|}{ Histology type } \\
\hline Adenocarcinoma & 11 & 24 & \multirow[t]{2}{*}{0.881} \\
\hline Squamous & 68 & 96 & \\
\hline \multicolumn{4}{|l|}{$\begin{array}{l}\text { Lymph node } \\
\text { metastasis }\end{array}$} \\
\hline No & 68 & 64 & \multirow[t]{2}{*}{$0.001^{\mathrm{a}}$} \\
\hline Yes & 21 & 56 & \\
\hline \multicolumn{4}{|l|}{ Distant metastasis } \\
\hline No & 76 & 85 & \multirow[t]{2}{*}{$0.019^{\mathrm{a}}$} \\
\hline Yes & 13 & 35 & \\
\hline \multicolumn{4}{|l|}{ Clinical stage } \\
\hline I-II & 74 & 81 & \multirow[t]{2}{*}{$0.011^{\mathrm{a}}$} \\
\hline III-IV & 15 & 39 & \\
\hline
\end{tabular}

$\mathrm{A} \chi^{2}$ test was performed to determine whether differences between the two groups were significant. ${ }^{\mathrm{a}} \mathrm{P}<0.05$.

when the score was $\geq 1$ and low when the score was $<1$. To compare the expression of Annexin A2 between adjacent and tumor tissues, Annexin A2 expression was normalized to the average score in normal tissues.

Statistical analysis. All data are expressed as the mean \pm standard deviation. SPSS 16.0 software (SPSS, Inc., Chicago, IL, USA) was used for statistical analysis. Student's t test was used to analyze the differential expression of Annexin A2 between laryngeal cancer tissue and adjacent normal tissue. A $\chi^{2}$ test was used to analyze the association between Annexin A2 expression and the clinicopathological parameters of patients with laryngeal cancer. Kaplan-Meier analysis with a log-rank test was used to examine the association between serum levels of Annexin A2 and overall survival (OS). The overall survival (OS) was defined as the time from diagnosis to the date of death or the date last known alive. The patients were followed 


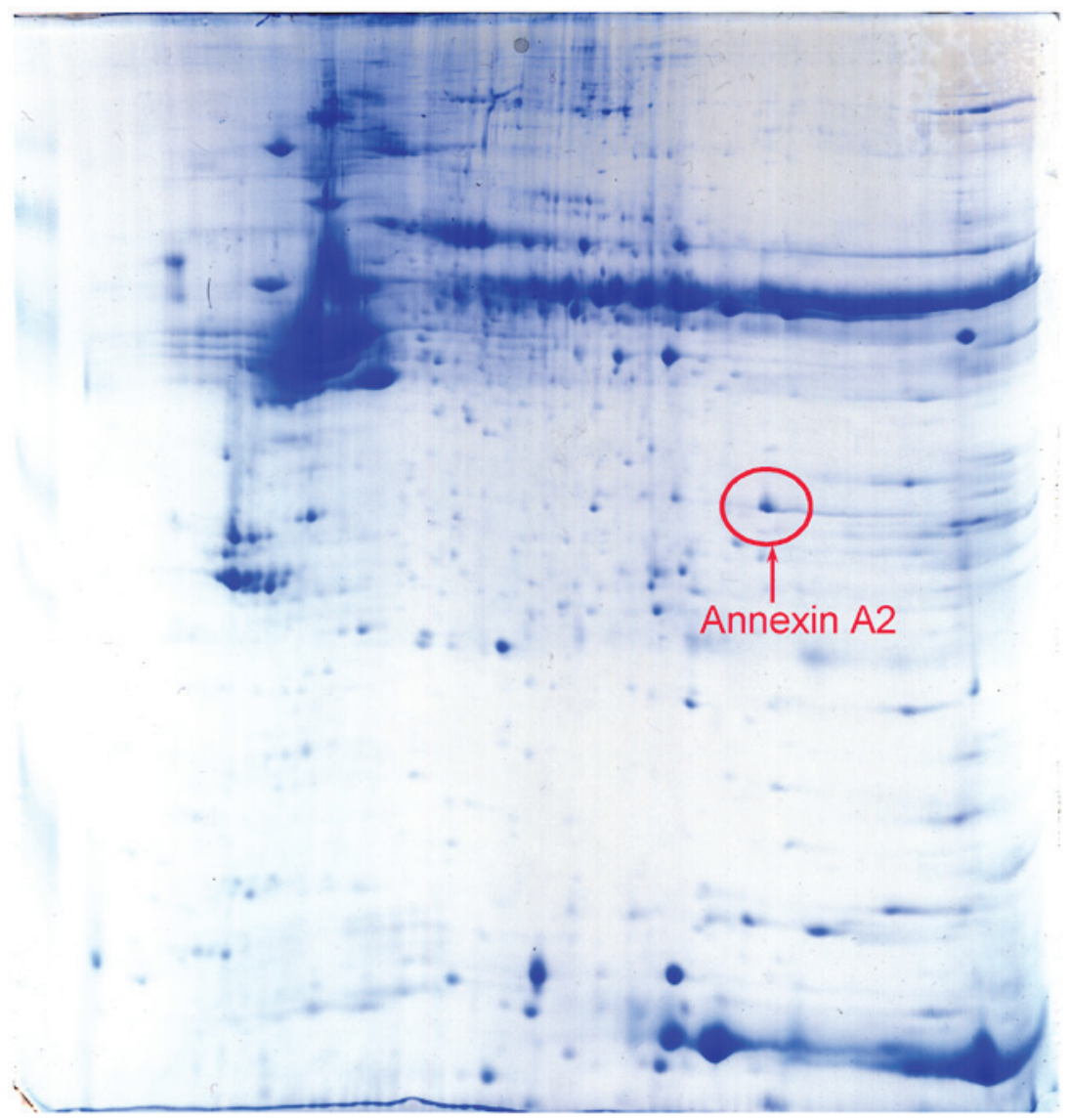

Figure 1. Three differential protein spots from two-dimensional polyacrylamide gel electrophoresis gels stained with Coomassie Brilliant Blue were identified as Annexin A2 by differential proteomics analysis and it was determined that this protein was overexpressed in human laryngeal carcinoma tissues.
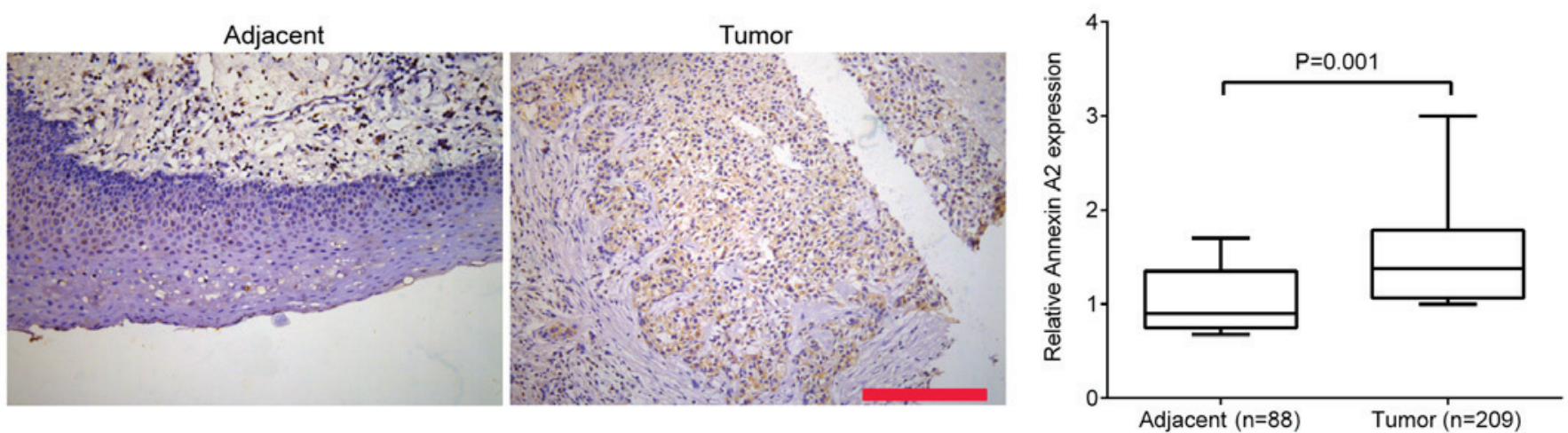

Figure 2. Annexin A2 was further identified as positively expressed by immunohistochemical staining analysis with diaminobenzidine staining and its expression was significantly higher in human laryngeal carcinoma tissues compared with adjacent tissues $(\mathrm{P}=0.001)$. Magnification, $\mathrm{x} 100$.

up every two months for five years. All the patients completed the follow-up. Finally, the cox proportional hazard regression model was used to estimate the independent predicators for the prognosis of patients with laryngeal cancer. $\mathrm{P}<0.05$ was considered to indicate a statistically significant difference.

\section{Results}

The expression of Annexin A2 is higher in laryngeal cancer tissues than in adjacent healthy tissue. Proteins from 5 human laryngeal cancer tissues and 5 matched adjacent normal tissues were run in duplicate using difference gel electrophoresis together with an internal pool sample on each gel. DeCyder software determined that the positional deviation of the protein spot was $1.67 \pm 0.24 \mathrm{~mm}$ for IEF and $1.25 \pm 0.13 \mathrm{~mm}$ for 2-DE. Fully automated spot detection and quantification were also conducted using the Decyder software ( $>1.5$ fold). Among the differential proteins detected, it was identified that Annexin A2 was overexpressed in cancer tissues (Fig. 1). Additionally, IHC staining was performed to measure the expression of Annexin A2 in the 209 laryngeal cancer tissues and 88 adjacent tissues. It was demonstrated that Annexin A2 expression was significantly higher in laryngeal cancer tissue compared with adjacent healthy tissues ( $\mathrm{P}=0.001$; Fig. 2). 
Table II. Univariate analysis of prognostic factors of laryngeal cancer.

\begin{tabular}{lcc}
\hline Variables & $\begin{array}{c}\text { Hazard } \\
\text { ratio }\end{array}$ & P-values \\
\hline Age ( $\geq 60 /<60$ years) & 1.391 & 0.669 \\
Sex (male/female) & 1.115 & 0.713 \\
Tumor size ( $\geq 5 /<5 \mathrm{~cm})$ & 2.733 & $0.014^{\mathrm{a}}$ \\
Histological grade (II-III/I) & 1.562 & 0.063 \\
Histology type (adenocarcinoma/ & 1.096 & 0.758 \\
squamous) & & \\
Lymph node metastasis (yes/no) & 4.256 & $0.005^{\mathrm{a}}$ \\
Distant metastasis (yes/no) & 3.511 & $0.011^{\mathrm{a}}$ \\
Clinical stage (III-IV/I-II) & 3.221 & $0.009^{\mathrm{a}}$ \\
Annexin A2 expression & 2.653 & $0.018^{\mathrm{a}}$ \\
(high/low) & & \\
\hline
\end{tabular}

${ }^{\mathrm{a}} \mathrm{P}<0.05$

Table III. Multivariate analysis of independent prognostic factors of laryngeal cancer.

\begin{tabular}{lcc}
\hline Variables & Hazard ratio & P-values \\
\hline Tumor size & 2.153 & $0.037^{\mathrm{a}}$ \\
Lymph node metastasis & 2.958 & $0.013^{\mathrm{a}}$ \\
Distant metastasis & 3.316 & $0.002^{\mathrm{a}}$ \\
Clinical stage & 2.718 & $0.018^{\mathrm{a}}$ \\
Annexin A2 expression & 3.643 & $0.001^{\mathrm{a}}$ \\
\hline
\end{tabular}

${ }^{\mathrm{a}} \mathrm{P}<0.05$

Expression of Annexin A2 is significantly associated with tumor size, clinical stage and lymph node metastasis in laryngeal cancer. The association between Annexin A2 expression and the clinical characteristics of patients with laryngeal cancer was further investigated. All patients with laryngeal cancer were divided into two groups: A high Annexin A2 expression group (score $\geq 1$ ) and a low Annexin A2 expression (score $<1$ ) group, according to the final staining score. As presented in Table I, it was demonstrated that there were no associations between Annexin A2 expression and age $(\mathrm{P}=0.674)$, sex $(\mathrm{P}=0.779)$, histological grade $(\mathrm{P}=0.460)$ or histology type $(\mathrm{P}=0.881)$. However, high Annexin 2 expression was significantly associated with tumor size $(\mathrm{P}<0.001)$, lymph node metastasis $(P=0.001)$, distant metastasis $(\mathrm{P}=0.019)$ and clinical stage $(\mathrm{P}=0.011)$. These results indicate that Annexin A2 expression may be used as a prognostic biomarker in the evaluation of the malignant progression of laryngeal cancer.

High Annexin A2 expression is associated with poor 5-year survival rates in patients with laryngeal cancer. The association between Annexin A2 expression and the survival rate was investigated in patients with laryngeal cancer using the

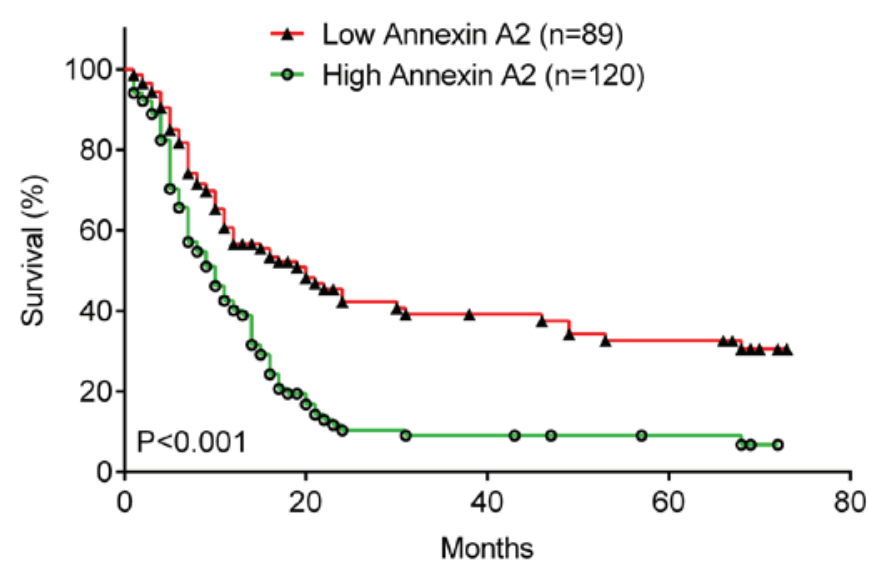

Figure 3. Association between Annexin A2 expression and the overall survival rate of patients with laryngeal carcinoma. The survival rate of patients in the high Annexin A2 expression group was significantly lower than that of patients in the low Annexin A2 expression group $(\mathrm{P}<0.001)$.

Kaplan-Meier method. It was demonstrated that the 5-year OS rate of patients with laryngeal cancer with high Annexin A2 expression was significantly lower (Fig. 3; P<0.001) than that of patients with low Annexin A2 levels. Therefore, high Annexin A2 expression is associated with poor prognosis in patients with laryngeal cancer.

In addition, the factors that could predicate the prognosis of laryngeal cancer patients were investigated using univariate and multivariate analyses. The results of the univariate analysis indicated that Annexin A2 expression $(\mathrm{P}=0.018)$, as well as tumor size $(\mathrm{P}=0.014)$, lymph node metastasis $(\mathrm{P}=0.005)$, distant metastasis $(\mathrm{P}=0.011)$ and clinical stage $(\mathrm{P}=0.009)$ were significantly associated with the survival of patients (Table II). Furthermore, Annexin A2 expression $(\mathrm{P}=0.001)$, tumor size $(\mathrm{P}=0.037)$, lymph node metastasis $(\mathrm{P}=0.013)$, distant metastasis $(\mathrm{P}=0.002)$ and clinical stage $(\mathrm{P}=0.018)$ were identified as independent factors for predicating the prognosis of patients with laryngeal cancer (Table III).

\section{Discussion}

Laryngeal squamous cell carcinoma accounts for $85-90 \%$ of all cases of laryngeal cancer and the mortality rate of patients with larynx adenocarcinomas is high (14). In 2012, 157,000 novel cases of laryngeal carcinoma were diagnosed and $\sim 1 \%$ of all cancer-associated mortalities are estimated to be from laryngeal carcinoma (15). Due to the lack of a definitive method of diagnosis and a frequent rate of recurrence, the prognosis of patients with advanced laryngeal cancer remains poor (2). In addition, many patients develop resistance to chemotherapy or radiotherapy, contributing to the high mortality rate (3). Therefore, it is necessary to improve understanding of the underlying molecular mechanisms of laryngeal carcinoma and to identify more effective diagnostic techniques and therapeutic targets.

Annexin A2, a calcium- and phospholipid-dependent protein, is widely distributed in the nucleus, cytoplasm and extracellular surface, and is primarily expressed in endothelial cells, macrophages and tumor cells (11). Annexin A2 orchestrates multiple biological processes and clinical associations, particularly during cancer progression (16). It has been 
demonstrated that Annexin A2 dysregulation is associated with the onset, invasion, metastasis and drug resistance of cancer (17). Furthermore, it has been suggested that Annexin A2 may be used as a potential biomarker for the diagnosis, treatment and prognosis of tumors (18). Zhang et al (18) reported that the soluble Annexin A2 concentration detected by ELISA in serum samples from 42 patients with lung cancer was significantly higher than in 43 healthy individuals. Furthermore, it has been demonstrated that Annexin A2 is upregulated in hepatocellular carcinoma tissues and serum samples compared with benign liver disease samples and its expression is associated with differentiated degree, intrahepatic metastasis and tumor node metastasis staging (19). These results indicate that Annexin 2 may be an independent prognostic factor for hepatocellular carcinoma (20). Previous studies have demonstrated that the expression of Annexin A2 is significantly associated with metastasis and poor survival in nasopharyngeal and endometrial carcinoma, bladder cancer and serous ovarian cancer (21-24). Using a proteomic assay, the present study identified that Annexin A2 was highly expressed in laryngeal carcinoma tissues, consistent with the results of the aforementioned studies. This high expression of Annexin 2 was confirmed by IHC staining. Furthermore, the expression of Annexin A2 was significantly associated with tumor size, lymph node and distant metastasis and the clinical stage. Therefore, the results of the current study indicated that high Annexin A2 expression is associated with poor prognosis in patients with laryngeal cancer, suggesting that Annexin A2 may act as an independent prognostic biomarker for evaluating the malignant progression of laryngeal cancer. Measuring the expression of Annexin A2 as well as the expression of other Annexins, including Annexins A4 and A3, may accurately predict the prognosis of different types of cancer, including urothelial carcinoma and cervical cancer $(11,25,26)$. The predictive efficiency of Annexin A2 combined with other Annexins in laryngeal carcinoma requires further investigation.

Mechanically, silencing of Annexin A2 expression suppresses cell proliferation, adhesion, migration, invasion and vascular formation in nasopharyngeal carcinoma cells by downregulating epithelial-mesenchymal transition-associated signaling proteins (22). Decreased expression of Annexin A2 causes defects in tumor growth in vivo and cell proliferation in vitro without causing cytotoxicity. This occurs by the induction of cell cycle arrest at the G2 phase in non-small cell lung cancer cells and esophageal squamous cell carcinoma, which occur in a p53-dependent or -independent manner $(27,28)$. Furthermore, it has been demonstrated that decreased Annexin A2 expression alters cell polarity, disrupts the formation of actin filaments and reduces $\mathrm{C}-\mathrm{X}-\mathrm{C}$ chemokine receptor type 4 expression via the Rho/Rock pathway in renal cell carcinoma (29). However, further studies are required to determine the mechanism by which Annexin A2 promotes the development of laryngeal cancer.

In conclusion, to the best of our knowledge, the current study is the first to demonstrate that Annexin A2 is upregulated in laryngeal cancer and high Annexin A2 expression is significantly associated with malignant progression and poor prognosis in patients with laryngeal cancer. Therefore, the expression of Annexin A2 may be a potential predictor for the prognosis of patients with laryngeal cancer.

\section{Acknowledgements}

The present study was supported by the National Natural Science Foundation of China (grant no. 81302355), the National Natural Science Foundation of China (grant no. 81201740) and Natural Science Foundation of Hunan Province (grant no. 2013FJ4225) and Xiangya Famous Doctors Foundation.

\section{References}

1. Li P, Liu H, Wang Z, He F, Wang H, Shi Z, Yang A and Ye J: MicroRNAs in laryngeal cancer: Implications for diagnosis, prognosis and therapy. Am J Transl Res 8: 1935-1944, 2016.

2. Gama RR, Carvalho AL, Longatto Filho A, Scorsato AP, López RV, Rautava J, Syrjänen S and Syrjänen K: Detection of human papillomavirus in laryngeal squamous cell carcinoma: Systematic review and meta-analysis. Laryngoscope 126: 885-893, 2016.

3. Greco A, Rizzo MI, De Virgilio A, Gallo A, Fusconi M Pagliuca G, Martellucci S, Turchetta R and De Vincentiis M: Cancer stem cells in laryngeal cancer: What we know. Eur Arch Otorhinolaryngol 273: 3487-3495, 2016.

4. Wang CY and Lin CF: Annexin A2: Its molecular regulation and cellular expression in cancer development. Dis Markers 2014: 308976, 2014.

5. Guo C, Liu S and Sun MZ: Potential role of Anxal in cancer. Future Oncol 9: 1773-1793, 2013.

6. Wu N, Liu S, Guo C, Hou Z and Sun MZ: The role of Annexin A3 playing in cancers. Clin Transl Oncol 15: 106-110, 2013.

7. Alves VA, Nonogaki S, Cury PM, Wünsch-Filho V, de Carvalho MB, Michaluart-Júnior P, Moyses RA, Curioni OA, Figueiredo DL, Scapulatempo-Neto C, et al: Annexin A1 subcellular expression in laryngeal squamous cell carcinoma. Histopathology 53: 715-727, 2008.

8. Wang KL, Wu TT, Resetkova E, Wang H, Correa AM, Hofstetter WL, Swisher SG, Ajani JA, Rashid A, Hamilton SR and Albarracin CT: Expression of annexin A1 in esophageal and esophagogastric junction adenocarcinomas: Association with poor outcome. Clin Cancer Res 12: 4598-4604, 2006.

9. Zhang J, Guo B, Zhang Y, Cao J and Chen T: Silencing of the annexin II gene down-regulates the levels of S100A10, c-Myc, and plasmin and inhibits breast cancer cell proliferation and invasion. Saudi Med J 31: 374-381, 2010.

10. Huang Y, Jin Y, Yan CH, Yu Y, Bai J, Chen F, Zhao YZ and Fu SB: Involvement of Annexin A2 in p53 induced apoptosis in lung cancer. Mol Cell Biochem 309: 117-123, 2008.

11. Deng S, Wang J, Hou L, Li J, Chen G, Jing B, Zhang X and Yang Z: Annexin A1, A2, A4 and A5 play important roles in breast cancer, pancreatic cancer and laryngeal carcinoma, alone and/or synergistically. Oncol Lett 5: 107-112, 2013.

12. Yang J, Zhou M, Zhao R, Peng S, Luo Z, Li X, Cao L, Tang K, Ma J, Xiong W, et al: Identification of candidate biomarkers for the early detection of nasopharyngeal carcinoma by quantitative proteomic analysis. J Proteomics 109: 162-175, 2014.

13. Luo Y, Wang X, Wang H, Xu Y, Wen Q, Fan S, Zhao R, Jiang S, Yang J, Liu Y, et al: High Bak Expression Is Associated with a Favorable Prognosis in Breast Cancer and Sensitizes Breast Cancer Cells to Paclitaxel. PLoS One 10: e138955, 2015.

14. Thompson LD: Laryngeal dysplasia, squamous cell carcinoma, and variants. Surg Pathol Clin 10: 15-33, 2017.

15. Mannelli G, Cecconi L and Gallo O: Laryngeal preneoplastic lesions and cancer: Challenging diagnosis. Qualitative literature review and meta-analysis. Crit Rev Oncol Hematol 106: 64-90, 2016.

16. Xu XH, Pan W, Kang LH, Feng H and Song YQ: Association of annexin A2 with cancer development (Review). Oncol Rep 33: 2121-2128, 2015.

17. Lauritzen SP, Boye TL and Nylandsted J: Annexins are instrumental for efficient plasma membrane repair in cancer cells. Semin Cell Dev Biol 45: 32-38, 2015.

18. Zhang X, Liu S, Guo C, Zong J and Sun MZ: The association of annexin A2 and cancers. Clin Transl Oncol 14: 634-640, 2012.

19. El-Abd N, Fawzy A, Elbaz T and Hamdy S: Evaluation of annexin A2 and as potential biomarkers for hepatocellular carcinoma. Tumour Biol 37: 211-216, 2016. 
20. Zhang H, Yao M, Wu W, Qiu L, Sai W, Yang J, Zheng W, Huang $\mathrm{J}$ and Yao D: Up-regulation of annexin A2 expression predicates advanced clinicopathological features and poor prognosis in hepatocellular carcinoma. Tumour Biol 36: 9373-9383, 2015.

21. Lokman NA, Pyragius CE, Ruszkiewicz A, Oehler MK and Ricciardelli C: Annexin A2 and S100A10 are independent predictors of serous ovarian cancer outcome. Transl Res 171: 83-95, 2016.

22. Chen CY, Lin YS, Chen CL, Chao PZ, Chiou JF, Kuo CC, Lee FP, Lin YF, Sung YH, Lin YT, et al: Targeting annexin A2 reduces tumorigenesis and therapeutic resistance of nasopharyngeal carcinoma. Oncotarget 6: 26946-26959, 2015.

23. Deng L, Gao Y, Li X, Cai M, Wang H, Zhuang H, Tan M, Liu S, Hao $\mathrm{Y}$ and Lin B: Expression and clinical significance of annexin A2 and human epididymis protein 4 in endometrial carcinoma. J Exp Clin Cancer Res 34: 96, 2015.

24. $\mathrm{Hu} \mathrm{H}$, Zhao $\mathrm{J}$ and Zhang M: Expression of annexin A2 and its correlation with drug resistance and recurrence of bladder cancer. Technol Cancer Res Treat 15: NP61-NP68, 2016.
25. Choi CH, Chung JY, Chung EJ, Sears JD, Lee JW, Bae DS and Hewitt SM: Prognostic significance of annexin A2 and annexin A4 expression in patients with cervical cancer. BMC Cancer 16: 448, 2016.

26. Lu CM, Lin JJ, Huang HH, Ko YC, Hsu JL, Chen JC, Din ZH and $\mathrm{Wu}$ YJ: A panel of tumor markers, calreticulin, annexin A2, and annexin A3 in upper tract urothelial carcinoma identified by proteomic and immunological analysis. BMC Cancer 14: 363, 2014.

27. Wang CY, Chen CL, Tseng YL, Fang YT, Lin YS, Su WC, Chen CC, Chang KC, Wang YC and Lin CF: Annexin A2 silencing induces $\mathrm{G} 2$ arrest of non-small cell lung cancer cells through p53-dependent and -independent mechanisms. J Biol Chem 287: 32512-32524, 2012.

28. Li X, Zheng S, Liu Q, Liu T, Liang M, Gao X, Lu M, Sheyhidin I and $\mathrm{Lu} \mathrm{X}$ : Under-expression of annexin A2 is associated with Kazakh's esophageal squamous cell carcinoma. Mol Carcinog 54: 779-788, 2015.

29. Yang SF, Hsu HL, Chao TK, Hsiao CJ, Lin YF and Cheng CW: Annexin A2 in renal cell carcinoma: Expression, function, and prognostic significance. Urol Oncol 33: 22, 2015 